\title{
Screening for pod shattering in mutant population of mungbean (Vigna radiata (L.) Wilczek)
}

\section{N. Vairam*, S. Anandhi Lavanya and C. Vanniarajan}

Department of Plant Breeding and Genetics, Agricultural College and Research Institute, Tamil Nadu Agricultural University, Madurai - 625104 (Tamil Nadu), INDIA

*Corresponding author. E-mail: vairamagri@gmail.com

Received: October 17, 2016; Revised received: April 13, 2017; Accepted: August 22, 2017

Abstract: Mungbean, (Vigna radiata (L.) Wilczek) occupies a unique position in Indian agriculture and has been grown under various agro-ecological conditions. It is cultivated in $1.61 \mathrm{mha}$ with production of $3.38 \mathrm{MT}$ and productivity of $474 \mathrm{~kg} / \mathrm{ha}$ in India. Mungbean pods are thin and brittle when dry, so shattering is a major problem. The loss of seeds by pod dehiscence is one of the major reasons for low yield in mungbean; thus, reducing the frequency of pod dehiscence is an important objective in mungbean breeding. Induced mutations, have offered a single and short alternative to conventional breeding including isolation, screening, selection and testing generation after generation. In this study, variability was induced by gamma rays and Ethyl methane sulphonate (EMS) in two greengram genotypes viz., $\mathrm{CO}(\mathrm{Gg}) 7$ and NM 65. Screening for pod shattering was carried out in $\mathrm{M}_{2}$ and $\mathrm{M}_{3}$ populations of greengram. The scoring for shattering was recorded at physiological maturity of the pod. The shattering percentage ranged from $14.56(400 \mathrm{~Gy})$ to 93.45 per cent $(20 \mathrm{mM})$. A total of 100 shattering tolerant mutants were selected from field based on visual observation. These mutants were again scored under laboratory condition as per IITA method. A total of 12 mutants of $\mathrm{CO}(\mathrm{Gg}) 7$ and 10 mutants of NM 65 which were tolerant to pod shattering were identified in $\mathrm{M}_{2}$ generation and forwarded to $\mathrm{M}_{3}$ generation. These mutants were scored for pod shattering under laboratory condition and nine mutants viz., M26, M44, M46, M58, M70, M71, M84, M92 and M98 were found to be tolerant in $M_{3}$ generation. This study on identification and screening of the mutants tolerant to pod shattering with high yielding potential will help to increase the production of the pods to a greater extent.

Keywords: Induced mutation, Mungbean, Pod shattering, Scoring, Elite mutants

\section{INTRODUCTION}

Legumes generally loose different alleles for high productivity, seed quality, pests and disease resistance during the processes of adaptation to environmental stress. A large number of legume species hitherto unexploited possess great potential for contributing to not only protein rich food for humans, but also excellent quality forage for animals. Among such novel legumes, mungbean (Vigna radiata (L.) Wilczek), belonging to family Fabaceae is quite notable (Wani et $a l ., 2012$ ). Mungbean is a cheap source of dietary protein for the poor, with high levels of folate and iron compared with many other legumes.

In Pulses, pod shattering is a major concern for the breeder. Pod shattering, when crops reach maturity in hot and dry condition could lead to serious seed yield losses (Adeyeye et al., 2014). Shattering resistance is one of the primary traits that crops have acquired in the process of domestication (Fuller 2007). Seed loss is generally divided into two periods, shattering before and during harvesting (Chandler et al., 2005). Seed losses of $34-99 \%$ are often associated with pod shattering in susceptible varieties and delayed harvesting af- ter maturity (Tiwari and Bhatnagar, 1991). This problem of mechanical damage is likely to be much affected by other plant attributes such as pod angles, pod length and width (Thompson and Hughes, 1986). So that breeding should be concentrate on development of high yielding varieties with pod shattering resistance. Hence screening the genotypes for pod shattering resistance is the initial process of crop breeding programme. The loss of seeds by pod dehiscence is one of the major reasons for low yield in mungbean; thus, reducing the frequency of pod dehiscence is an important objective in mungbean breeding. Most of the mungbean genotypes are prone to shattering. The indeterminate flowering habit of this crop leads to a spread of flowering and pod maturity on a single plant over the entire reproductive phase. Consequently, pods which develop at the earliest flower may shatter prior to $100 \%$ pod maturity. Mutation breeding is a proven supplement and an effective substitute of conventional breeding so as to confer specific improvement in a variety without significantly affecting its acceptable phenotype (Sanjay Gandhi et al., 2014). Although selection for economically useful spontaneous mutants still takes place with some level of success (Wilde et 
al., 2012), the purposeful induction of a specifically desired mutation at a specific time and place, and in a selected genotype for a selected purpose is a much more attractive option. Induced mutation is a suitable source of producing variation through mutation breeding pro-cedure (Domingo et al., 2007). Mutated genes have therefore; become valuable material to plant breeders and molecular biologists for understanding not only the function but also in shuffling and isolating the genes between varieties (Souframanian et al., 2002). Mutation breeding offers scope for achieving in many instances what cannot be accomplished through backcross breeding and selection (Lavanya et al., 2011). Induced mutation using physical and chemical mutagens is one way to create genetic variation resulting in new varieties with better characteristics. The practical role of induced mutation in the improvement of crop plants can best be assessed on the basis of quantitatively inherited characters. It combines quite a few advantages in plant improvement by up- grading an explicit character without altering the original genetic makeup of the cultivar. In that sense, it provides a speedy method to improve the crop varieties, without resorting to hybridization and back crossing. The identification of resistant sources for pod shattering is one of the most important aspects in the management of pod shattering. Hence the present investigation was carried out with Mutant population of greengram for screening of elite mutants tolerant to pod shattering.

\section{MATERIALS AND METHODS}

Two greengram genotypes viz., Co (Gg) 7 and NM 65 obtained from the Department of Pulses, Centre for Plant Breeding and Genetics, TNAU, Coimbatore. The genotypes were subjected to gamma irradiation at the doses of 400, 500 and 600 Gray and Ethyl Methane Sulphonate treatments of 10, 20 and 30 milli Molar. Gamma irradiation was done using cobalt 60 sources in the Gamma chamber, installed at Centre for Plant Breeding and Genetics, TNAU, Coimbatore. The chemical mutagen, ethyl methane sulphonate $\left(\mathrm{CH}_{3} \mathrm{SO}_{2} \mathrm{OC}_{2} \mathrm{H}_{5}\right)$ with molecular weight 124.16 , from the sigma chemical company, USA was used for treating the seeds. The treated seeds were sown with a spacing of $30 \times 10 \mathrm{~cm}$ in a randomized block design. The trial was conducted in the research farm of Agricultural College and Research Institute, Madurai during Kharif season 2013. The weather in the site is usually warm and dry with the mean annual rainfall of $851 \mathrm{~mm}$ and a maximum and minimum temperature of $35.5^{\circ} \mathrm{C}$ and $23.5^{\circ} \mathrm{C}$, respectively. The $\mathrm{M}_{2}$ generation was raised as individual $\mathrm{M}_{1}$ plant basis. The $\mathrm{M}_{3}$ generation was raised under Randomized Block Design. The treated and control populations of $\mathrm{M}_{2}$ and $\mathrm{M}_{3}$ generation were carefully screened for pod shattering resistance.

Screening for pod shattering resistance: Pod shattering resistance was evaluated both in laboratory and

field conditions and found out that laboratory method is not influenced by the environment and hence can only be used as a tool for identification of pod shattering resistance genotypes Agarwal et al. (2000). The pod shattering resistance was recorded at physiological maturity of the pod. The screening was done under laboratory condition by following the methodology adopted by IITA (Dashell and Bello, 1988). The results were recorded as percentage of pod shattering.

IITA method of calculating pod shattering under lab conditions:

A sample of 25 pods were collected and kept in oven at $40^{\circ} \mathrm{C}$ for 7 days.

On the $7^{\text {th }}$ day, the number of shattered pods were counted and expressed in percentage as below,

Pod shattering percentage $(\%)=$ Number of pods shattered / Total number of pods x 100

The genotypes were classified into different categories based on their reaction to pod shattering. The scoring rate was followed according to method adopted by IITA.

\section{Category}

No pod shattering

$<25 \%$ pod shattering

$25-50 \%$ pod shattering

$51-75 \%$ pod shattering

$>75 \%$ pod shattering

\section{RESULTS AND DISCUSSION}

Induced mutations are also useful when it is desired to improve easily identifiable characters (Roychowdhury and Tah, 2013). Mutant plants displayed a range of reduction in shattering ( 5 to $15 \%$ ) depending upon the combination of mutations used. This variation is being utilized for variety development.

Visual screening is the most effective and efficient method for identifying mutant phenotypes. In the present study, hundred mutants were selected based on field observations to shattering. Similar method of screening was reported by Yamada, et al. (2009) and Khan et al. (2013) in Soyabean. Under laboratory condition, the lowest pod shattering percentage was recorded by the mutants, M77 $(30 \mathrm{mM})$ of CO $(\mathrm{Gg}) 7$ and M58 (400 Gy) of NM 65. Highest shattering percentage was recorded by the mutants M1 (300 Gy) of CO (Gg) 7 and M95 (20 mM) of NM 65. Similar findings were given by Mohammad (2010) and Khan et al. (2013) in Soyabean. CO (Gg) 7 was under very highly shattering type $(76.56 \%)$ and NM 65 showed highly shattering percentage of $67 \%$ in $\mathrm{M}_{2}$ generation.

Among the 100 mutants, 22 mutants were identified as tolerant types, 42 mutants observed to be medium shattering, 29 mutants showed highly shattering and $7 \mathrm{mu}-$ tants falls under very highly shattering categories. These findings are similar to genotypic studies in Soyabean given by Gadde (2006), Khan et al. (2013). None of the mutants showed resistance to pod shatter- 
N. Vairam et al. / J. Appl. \& Nat. Sci. 9 (3): 1787 -1791 (2017)

Table 1. Screening for pod shattering in $\mathrm{M}_{2}$ mutant lines of greengram.

\begin{tabular}{|c|c|c|c|c|c|c|c|}
\hline Mutants & Treatments & Shattering \% & Grade & Mutants & Treatments & Shattering \% & Grade \\
\hline \multirow[t]{2}{*}{$\overline{\mathrm{M} 1}$} & \multirow{5}{*}{$\mathrm{CO}(\mathrm{Gg}) 7$} & 83.54 & Very highly shattering & $\overline{\mathrm{M} 46}$ & \multirow{5}{*}{$\begin{array}{l}\text { NM } 65 \\
300 \text { Gy }\end{array}$} & 22.98 & Tolerant \\
\hline & & & & M47 & & 24.45 & Tolerant \\
\hline M2 & & 75.08 & Highly shattering & M48 & & 45.00 & Moderately shattering \\
\hline \multirow[t]{2}{*}{ M3 } & & 80.67 & Very highly shattering & M49 & & 43.66 & Moderately shattering \\
\hline & & & & M50 & & 42.81 & Moderately shattering \\
\hline M4 & \multirow{3}{*}{300 Gy } & 65.89 & Highly shattering & M51 & & 31.99 & Moderately shattering \\
\hline M5 & & 23.12 & Tolerant & M52 & & 30.00 & Moderately shattering \\
\hline M6 & & 76.34 & Very highly shattering & M53 & & 32.88 & Moderately shattering \\
\hline M7 & & 70.88 & Highly shattering & M54 & & 15.00 & Tolerant \\
\hline \multirow{2}{*}{ M8 } & & 43.28 & Moderately shattering & M55 & & 17.87 & Tolerant \\
\hline & & 45.20 & 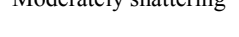 & M56 & \multirow[b]{2}{*}{ NM 65} & 32.10 & Moderately shattering \\
\hline M9 & & 20.19 & Tolerant & M57 & & 46.76 & Moderately shattering \\
\hline \multirow{2}{*}{ M10 } & & 50.90 & Moderately shattering & M58 & \multirow[b]{2}{*}{400 Gy } & 14.56 & Tolerant \\
\hline & & 50.90 & 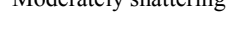 & M59 & & 53.89 & Highly shattering \\
\hline \multirow[t]{2}{*}{ M11 } & & 34.00 & Moderately shattering & M60 & & 67.87 & Highly shattering \\
\hline & & 2900 & 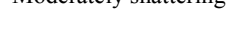 & M61 & NM 65 & 65.43 & Highly shattering \\
\hline M12 & & 53.25 & Highly shattering & M62 & \multirow{3}{*}{500 Gy } & 78.90 & Very highly shattering \\
\hline M13 & & 46.77 & Moderately shattering & M63 & & 53.22 & Highly shattering \\
\hline & & & & M64 & & 58.76 & Highly shattering \\
\hline M14 & & 49.08 & Moderately shattering & M65 & & 68.90 & Highly shattering \\
\hline & & & & M66 & & 25.00 & Tolerant \\
\hline M15 & & 27.89 & Moderately shattering & M67 & & 65.00 & Highly shattering \\
\hline & & & & M68 & $\mathrm{CO}(\mathrm{Gg}) 7$ & 43.98 & Moderately shattering \\
\hline M16 & & 30.84 & Moderately shattering & M69 & & 54.90 & Highly shattering \\
\hline & & & Highly shattering & M70 & $10 \mathrm{mM}$ & 22.87 & Tolerant \\
\hline M17 & & $\begin{array}{l}56.33 \\
23.99\end{array}$ & Highly shattering & M71 & & 21.94 & Tolerant \\
\hline M18 & & 23.99 & Tolerant & M72 & $\mathrm{CO}(\mathrm{Gg}) 7$ & 30.12 & Moderately shattering \\
\hline M19 & & 32.85 & Moderately shattering & M73 & & 35.44 & Moderately shattering \\
\hline M20 & $\mathrm{CO}(\mathrm{Gg}) 7$ & 25.62 & Moderately shattering & M74 & $20 \mathrm{mM}$ & 56.34 & Highly shattering \\
\hline & & & & M75 & & 32.14 & Moderately shattering \\
\hline M21 & 400 Gy & 26.78 & Moderately shattering & M76 & & 34.76 & \\
\hline & & & & & & & Moderately shattering \\
\hline M22 & & 39.00 & Moderately shattering & M77 & & 15.45 & Tolerant \\
\hline & & & & M78 & & 70.99 & Highly shattering \\
\hline M23 & & 25.52 & Moderately shattering & M79 & & 67.80 & Highly shattering \\
\hline & & & & M80 & & 45.00 & Moderately shattering \\
\hline M24 & & 35.67 & Moderately shattering & M81 & & 34.99 & \\
\hline & & & & & & & Moderately shattering \\
\hline M25 & & 42.32 & Moderately shattering & M82 & & 45.87 & Moderately shattering \\
\hline & & & & M83 & & 43.21 & Moderately shattering \\
\hline M26 & & 21.90 & Tolerant & M84 & & 15.45 & Tolerant \\
\hline M27 & & 40.75 & Moderately shattering & M85 & & 65.45 & Highly shattering \\
\hline M28 & & 56.78 & Highly shattering & M86 & & & Hiobly shattering \\
\hline M29 & & 34.56 & Moderately shattering & M87 & & 46.75 & Moderately shattering \\
\hline & & & & M88 & & 54.33 & Highly shattering \\
\hline M30 & & 30.00 & Moderately shattering & M89 & & 23.45 & Tolerant \\
\hline M31 & & 78.65 & Very highly shattering & M90 & & 35.90 & Moderately shattering \\
\hline & & & & M91 & & 24.00 & Tolerant \\
\hline M32 & & 73.21 & Highly shattering & M92 & & 20.98 & Tolerant \\
\hline M33 & $\mathrm{CO}(\mathrm{Gg}) 7$ & 65.77 & Highly shattering & M93 & & 45.43 & Moderately shattering \\
\hline M34 & & 62.09 & Highly shattering & M94 & & 65.80 & Highly shattering \\
\hline M35 & 500 Gy & 60.54 & Highly shattering & M95 & & 93.45 & Very highly shattering \\
\hline M36 & & 24.50 & Tolerant & M96 & & 48.70 & \\
\hline M37 & & 66.67 & Highly shattering & & & & Moderately shattering \\
\hline M38 & & 22.52 & Tolerant & M97 & & 35.78 & Moderately shattering \\
\hline M39 & & 77.00 & Very highly shattering & M98 & & 16.99 & Tolerant \\
\hline & & 11.00 & & M99 & & 26.55 & Moderately shattering \\
\hline M40 & & 69.43 & Highly shattering & M100 & & 32.00 & Moderately shattering \\
\hline M41 & & 50.97 & Moderately shattering & Co $(\mathrm{Gg}) 7$ & & 76.56 & \\
\hline & & & & & & & Very highly shattering \\
\hline M42 & & 23.00 & Tolerant & NM 65 & & 67.00 & \\
\hline M43 & & 54.68 & Highly shattering & & & & Highly shattering \\
\hline M44 & & 19.00 & Tolerant & Mean & & Range & \\
\hline M45 & & 70.32 & Highly shattering & 45.08 & & $14.56-93.45$ & \\
\hline
\end{tabular}

$<25 \%$ shattering- Tolerant, $25-50 \%$ - Moderately shattering, 51-75\%- Highly shattering, $>75 \%$ - Very highly shattering. 
Table 2. $\mathrm{M}_{3}$ mutants scoring for tolerance to pod shattering.

\begin{tabular}{|c|c|c|c|}
\hline Mutants & Treatments & Shattering \% & Grade \\
\hline M5 & $\mathrm{CO}(\mathrm{Gg}) 7$ & 45.67 & Moderately shattering \\
\hline M9 & 300 Gy & 64.44 & Highly shattering \\
\hline M18 & $\mathrm{CO}(\mathrm{Gg}) 7$ & 39.80 & Moderately shattering \\
\hline M26 & 400 Gy & 12.56 & Tolerant \\
\hline M36 & $\mathrm{CO}(\mathrm{Gg}) 7$ & 70.90 & Highly shattering \\
\hline M38 & $500 \mathrm{~Gy}$ & 57.89 & Highly shattering \\
\hline M42 & & 25.13 & Moderately shattering \\
\hline M44 & & 20.90 & Tolerant \\
\hline M46 & NM 65 & 13.56 & Tolerant \\
\hline M47 & 300 Gy & 33.78 & Moderately shattering \\
\hline M54 & & 27.89 & Moderately shattering \\
\hline M55 & & 26.67 & Moderately shattering \\
\hline M58 & NM 65 & 25.00 & Tolerant \\
\hline M66 & $400 \mathrm{~Gy}$ & 23.25 & Moderately shattering \\
\hline M70 & $\begin{array}{c}\mathrm{CO}(\mathrm{Gg}) 7 \\
10 \mathrm{mM}\end{array}$ & 10.90 & Tolerant \\
\hline M71 & $\begin{array}{c}\mathrm{CO}(\mathrm{Gg}) 7 \\
20 \mathrm{mM}\end{array}$ & 16.78 & Tolerant \\
\hline M77 & $\begin{array}{c}\mathrm{CO}(\mathrm{Gg}) 7 \\
30 \mathrm{mM}\end{array}$ & 28.90 & Moderately shattering \\
\hline M84 & $\begin{array}{l}\text { NM } 65 \\
10 \mathrm{mM}\end{array}$ & 22.88 & Tolerant \\
\hline M89 & NM 65 & 60.55 & Highly shattering \\
\hline M91 & $20 \mathrm{mM}$ & 27.65 & Moderately shattering \\
\hline M92 & & 23.12 & Tolerant \\
\hline M98 & $\begin{array}{l}\mathrm{NM} 65 \\
30 \mathrm{mM}\end{array}$ & 22.56 & Tolerant \\
\hline $\mathrm{V}_{1}$ Control & $\mathrm{CO}(\mathrm{Gg}) 7$ & 82.15 & Very highly shattering \\
\hline $\mathrm{V}_{2}$ Control & NM 65 & 60.45 & Highly shattering \\
\hline
\end{tabular}

ing. Gadde (2006) also found similar kind of results in Soyabean. Mutant plants displayed a range of reduction in shattering (5 to $15 \%$ ) depending upon the combination of mutations used. This variation is being utilized for variety development.

Agrawal et al. (2003) reported that segregation of pod shattering was highly complex in $\mathrm{F}_{2}$ generation in Soyabean and showed quantitative response in the cross of susceptible and resistant varieties and concluded that success of any conventional breeding program aimed at pod shattering resistance depends upon the desirable segregates.

Hence, 22 mutants identified as tolerant types have to be further evaluated in laboratory condition in succeeding generation.

The pod shattering tolerant types for gamma rays was found in 500 Gy for Co (gg) 7 and 300 Gy for NM 65 . All other doses show medium shattering percentage with the scale of 3 . In EMS, pod shattering tolerant types was found in $30 \mathrm{mM}$ for both the genotypes as 7.84 and 5.74 per cent respectively. Lower doses of $10 \mathrm{mM}$ and $20 \mathrm{~mm}$ are having the medium shattering percentage. The shattering percentage was higher in gamma rays than EMS in both the genotypes. None of the genotypes were immune or resistant to pod shattering in Soyabean (Gadde, 2006).

Screening of mutants for pod shattering revealed 22 mutants as tolerant types, 42 mutants as moderately shattering, 29 mutant as highly shattering and seven mutants falls under very highly shattering categories in $\mathrm{M}_{2}$ generation. The shattering percentage was higher in gamma rays than EMS in both the genotypes. In $\mathrm{M}_{3}$ generation, out of 22 tolerant mutants, $\mathrm{CO}(\mathrm{Gg})$
7 contains 12 mutants while 10 mutants belongs to NM 65. Eight mutants of $\mathrm{CO}(\mathrm{Gg}) 7$ viz., M5, M9, M18, M26, M36, M38, M42 and M44 and five mutants of NM 65 viz., M46, M47, M54, M55 and M58 were gamma irradiated population.

In EMS treatments, four mutants of $\mathrm{CO}(\mathrm{Gg}) 7$ viz., M66, M70, M71 and M77 for CO (Gg) 7, while five mutants of NM 65 namely M84, M89, M91, M92 and M98 fall under tolerant categories. Twenty two mutants were scored for pod shattering under laboratory condition and nine mutants viz., M26 (19.14\%), M44 (20.85\%), M46 (13.48\%), M58 (23.17\%), M70 (10.47\%), M71 (16.64\%), M84 (22.79\%), M92 $(23.11 \%)$ and M98 $(22.53 \%)$ were found to be tolerant in $\mathrm{M}_{3}$ generation. The control, $\mathrm{CO}(\mathrm{Gg}) 7$ scored under very highly shattering and NM 65 under highly shattering category. Similar results were reported by Bhara et al. (2013) in Soyabean. These shattering tolerant mutants can be further evaluated for yield contributing characters in succeeding generations for the selection of elite mutants for resistance to novel trait.

\section{Conclusion}

Pod shattering is one of the major constraints in greengram, which reduces the yield potential considerably. Hence, the identification of resistant sources for pod shattering is one of the most important aspects in the management of pod shattering. Mutagenesis is a well recognized potential tool to induce high genetic variability for effective selection towards improvement in yield and quality. Nine mutants of two genotypes of greengram were found to be tolerant to pod shattering. The identified mutants can be screened further and used in hybridization programme for development of resistant variety.

\section{REFERENCES}

Adeyeye, A.S., Togun, A.O., Akanbi, W.B., Adepoju, I.O. and Ibirinde, D.O. (2014). Pod shattering of different soybean varieties, Glycine max (L) Merrill, as affected by some growth and yield parameters. Int. J. Agric. Policy Res., 2(1): 010-015.

Agrawal A. P., Salimath, P. M. and Patil, S. A. (2003). Inheritance of pod shattering in soybean. Ind. J. Genet., 63: 265-266.

Agarwal, A.P., Patil, S.A. and Salimath, P.M. (2000). Identification of potential soybean genotypes for pod shattering resistance and seed yield. Crop Improvement., 27: 236-239.

Bhara, N., Khare, D. and Shrivastava, A.N. (2013). Studies on the factors affecting pod shattering in soybean. Indian J. Genet., 73(3): 270-277

Chandler, J., Corbesier, L., Spielmann, P., Dettendorfer, J., Stahl, D., Apel, K. and Melzer, S. (2005). Modulating flowering time and prevention of pod shatter in oilseed rape. Mol Breed., 15:87-94.

Dashell, K.E. and Bello, L. (1988). Screening for resistance to pod shattering. IITA Grain legume Improvement programme. Annual report for 1986. Nigeria, 
p. 120 .

Domingo, C., Andres, F. and Talon, M. (2007). Rice cv. 'Bahia' mutagenized population: a new resource for rice breeding in the Mediterranean basin. Spain $J$ Agric Res., 5: 341-347.

Fuller, D.Q. (2007). Contrasting patterns in crop domestication and domestication rates: recent archaeobotanical insights from the OldWorld. Annals of Botany., 100(5): 903-924

Gadde, P.M. (2006). Genetic investigations in Soybean (Glycine Max (1.) Merrill). M.Sc. (Ag.) Thesis, UAS, Dharwad.

IITA (1986). A laboratory method for evaluating resistance to pod shattering in soybeans. Annual Report IITA., 5859.

Khan, M. H., Tyagi, S.D. and Dar, Z.A. (2013). Screening of Soybean (Glycine Max (L.) Merrill) Genotypes for Resistance to Rust, Yellow Mosaic and Pod Shattering.http://dx.doi.org/10.5772/54697

Lavanya, G.R., Yadav, L., Suresh Babu, G. and Jyotipaul, P. (2011). Sodium azide mutagenic effect on biological parameters and induced genetic variability in mungbean. J. Food Leg., 24(1): 46-49

Mohammed, H. (2010). Genetic analysis of resistance to Pod Shattering in Soybean (Glycine max. (L) Merrill). M.Sc. (Ag.) Thesis, Kwame Nkrumah University of Science and Technology, Kumasi.

Roychowdhury, R. and Tah, J. (2013). Mutagenesis-A
Potential Approach for Crop Improvement. Crop Improvement., 4:149-187

Sanjay Gandhi, E., Umavathi, S. and Mullainathan, L. (2014). Studies on induced chlorophyll mutants in green gram (Vigna radiata (L.) Wilczek). International Journal of Advanced Research., 2(2): 00-04

Souframanian, J., Pawar, S.E. and Rucha, A.G. (2002). Genetic variation in gamma ray induced mutants in black gram as revealed by RAPD and ISSR markers. Indian J. Gent., 62(4): 291-295.

Thompson, K. F. and Huges, W.G. (1986). Breeding varieties. In: Scarisbrick D. H. Daniels, R. W.(eds). Oilseed Rape. Collins Professional and technical, pp. 32-82.

Tiwari, S. P. and Bhatnagar, P.S. (1991). Pod shattering as related to other agronomic attributes in soybean. Tropical Agriculture., 68:102-103.

Wani, M.R., S. Khan and M.I. Khozgar. 2012. Genetic enhancement of mungbean (Vigna radiata (L.) Wilczek).through induced mutagenesis. Crop Res., 43 (1, 2 \& 3): 189-193.

Wilde, H.D., Chen, Y., Jiang, P. and Bhattacharya, A. (2012). Targeted mutation breeding of horticultural plants. Emir J Food Agric., 24(1): 31-41

Yamada, T., Hideyuki Funatsuki, Seiji Hagihara, Shohei Fujita, Yoshinori Tanaka, Hiroyuki Tsuji, Masao Ishimoto, Kaien Fujino and Makita Hajika. (2009). A major QTL, qPDH1, commonly involved in shattering resistance of soybean Cultivars. Breeding Science., 59:435-440 